\title{
Seismic Evidence for Possible Slab Melting from Strong Scattering Waves
}

\author{
Cheng-Horng Lin \\ Institute of Earth Sciences, Academia Sinica, Taipei, Taiwan
}

Received 8 May 2010, accepted 23 July 2010

\begin{abstract}
Slab melting in young and hot subduction zones has been studied using geochemical observations and thermal modelling, but there are few data from seismic studies to confirm slab melting. Also the detailed geometry in the deep part of the melting slab is often ambiguous in that the intraslab earthquakes within the Wadati-Benioff zone are only limited to shallower depths. To improve our understanding of both the seismic features and geometry found in a young and hot subducted slab, I analyzed anomalous moonquake-like seismograms that were generated by an intermediate-depth earthquake recorded in central Japan. For this study, possible reflected (or scattered) sources were examined using detailed analyses of particle motions and a grid search for travel-time differences between the direct and later P-waves. The results show that using strong seismic scattering, slab melting is likely occurring in the deeper, flexing part of the subducted Philippine Sea plate. Because the subducted Philippine Sea plate in central Japan is young and therefore hot, partial melting might have taken place to produce abundant melting spots in the subducted slab. Melting spots, identified as "bright spots," could efficiently reflect or scatter seismic energy and generate many later phases with large amplitudes.
\end{abstract}

Key words: Slab melting, Strong scatter, Central Japan

Citation: Lin, C. H., 2011: Seismic evidence for possible slab melting from strong scattering waves. Terr. Atmos. Ocean. Sci., 22, 255-260, doi: 10.3319/ TAO.2010.07.23.01(T)

\section{INTRODUCTION}

Slab melting can take place when the subducted plate is young and warm (Defant and Drummond 1990). A wellstudied example is the subduction zone where the Philippine Sea plate is being subducted beneath southwestern Japan (Morris 1995; Peacock and Wang 1999). Geochemical analyses of volcanic lava show that the erupted magmas, termed "adakites," result from the melting of the young and warm Philippine Sea plate (Morris 1995). Also, the absence of intraslab earthquakes at depths greater than $70 \mathrm{~km}$ in southwestern Japan might be a consequence of aseismic ductile behavior at higher temperatures. These interpretations have been supported by integration of thermal modeling of subducting plates with analyses of mineral stabilities (Peacock and Wang 1999).

However, there is still no direct seismic evidence to show the physical behavior of partial melting in a subducted slab despite results from geochemical analyses and thermal

\footnotetext{
* Corresponding author

E-mail:lin@earth.sinica.edu.tw
}

modelling (Defant and Drummond 1990; Morris 1995; Peacock and Wang 1999). The absence of seismic evidence for slab melting is likely primarily attributed to the difficulty of detecting the melting of the subducting slab and lack of deep intraslab earthquakes. In general, seismic signatures of both the Wadati-Benioff zone and seismic velocity anomalies are two of the most important pieces of evidence to identify a subducted slab. For a melting slab, however, geometry of the subducted slab at depths greater than $70 \mathrm{~km}$ is difficult to know with certainty due to the absence of the Wadati-Benioff zone signature. Missed identification of the intermediate-depth intraslab earthquakes might also cause a serious problem because of a lack of seismic ray-paths to image the subducted slab by using either seismic tomography or other reflected and converted waves at the slab boundary. Furthermore, slab melting likely makes the signature of the velocity anomaly for the subducted plate ambiguous because the high velocity anomaly reflecting the relatively cold subducted slab will be obscured by partial melting. As a result, the seismic evidence for slab melting is difficult to obtain without also detecting deeper earthquakes. 
Two active subduction systems in central Japan provide an ideal opportunity to examine the possible geometry and melting features of the subducted slab (Seno et al. 1996; Noguchi 2002). The Pacific plate subducts westward beneath both the Okhotsk plate and the Philippine Sea plate along the Japan and Izu-Bonin trenches, respectively (Fig. 1). The geometry of the subducted Pacific plate can be unambiguously imaged from a plenty of earthquakes along the Wadati-Benioff zone (Noguchi 2002; Matsubara et al. 2008). The depths of the subducted Pacific plate increase westward, ranging from 80 to $300 \mathrm{~km}$ beneath central Japan. Conversely, the Philippine Sea plate subducts beneath the Okhotsk plate and the Eurasian plate along the Sagami and Suruga troughs, respectively. The geometry of the subducted Philippine Sea plate is not so clear because parts of the Wadati-Benioff zone signatures are missing (Ishida 1992; Obara 2002). Only some shallower earthquakes at depths from 20 to $90 \mathrm{~km}$ indicate the wavy configuration of the subducted Philippine Sea plate beneath central Japan (Noguchi 2002). Although no intermediate-depth earthquakes along the subduction of the Philippine Sea plate in central Japan have occurred, seismic waves from the deeper earthquakes associated with the subducted Pacific plate can be used to

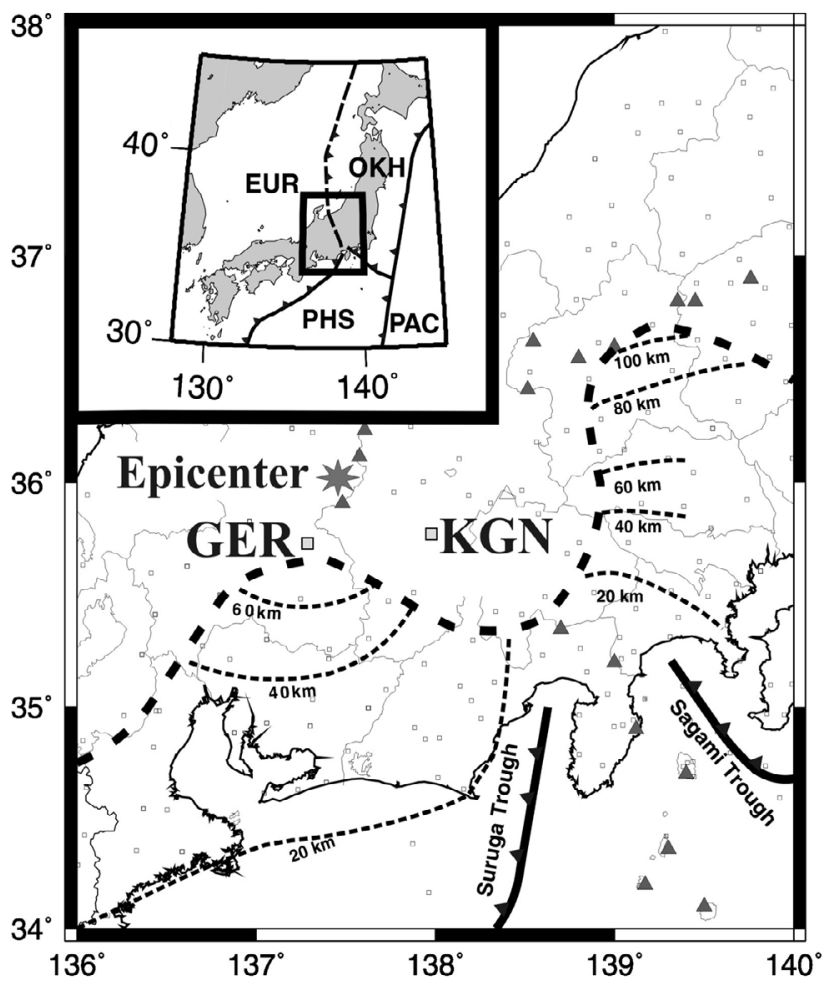

Fig. 1. General tectonics and locations of the Hi-net seismic stations (squares) and an intermediate-depth earthquake (star) in central Japan. The edge and iso-depth contours of the subducted Philippine Sea plate depicted by the Wadati-Benioff zone are shown by thick and thin dashed lines, respectively. Locations of active volcanoes are marked by triangles. The inset map at the left upper corner marks the location of the study area (box) in and around Japan. better understand the physical behavior of slab melting. In that study, detailed analyses of an anomalous moonquakelike seismogram (Lin et al. 2003) showed that the presence of abundant scattering sources in the upper mantle likely result from slab melting in the subducted Philippine Sea plate beneath central Japan.

\section{SEISMIC DATA}

The seismic data used in this study are anomalous seismograms (Lin et al. 2003) generated by an intermediatedepth earthquake and recorded by the National Research Institute for Earth Science and Disaster Prevention's (NIED) high-sensitivity seismograph network (Hi-net) in central Japan (Obara 2002; Okada et al. 2004; Obara et al. 2005). The earthquake ( $\mathrm{M}=4.6)$ was located by the Hi-net at longitude $137.4679^{\circ} \mathrm{E}$ and latitude $36.0456^{\circ} \mathrm{N}$ with a focal depth of $264 \mathrm{~km}$. An anomalous moonquake-like seismogram recorded at the KGN station $\left(137.9719^{\circ} \mathrm{E}, 35.7518^{\circ} \mathrm{N}\right)$, one of the Hi-net stations near the epicenter, shows many later phases continuously arrive after the first arrival. The amplitudes of those later phases do not significantly decay with time (Fig. 2) and appear more like seismograms recorded on the moon where abundant cracks in the upper crust act as strongly scattering sources (Nakamura et al. 1982), rather than those generated by ordinary mantle earthquakes, which often produce unambiguous $\mathrm{P}$-waves without a lot of strong later phases due to high homogeneous characteristics in the mantle. Careful comparisons of the anomalous seismograms from this event with other deep earthquakes have shown that the scattering sources were located neither at the upper crust nor near the hypocenter (Lin et al. 2003).

\section{DATA ANALYSES}

To constrain possible scattering sources for those later phases in the anomalous moonquake-like seismogram, particle motions of $\mathrm{P}$-wave arrivals in the first 5 seconds are examined (Figs. 3 and 4). As expected, the particle motion of the first arrivals (30.5 - $31.1 \mathrm{sec}$ ) (Fig. 4) on the horizontal plane is roughly shown along the azimuth direction (NWSE), which is consistent with the source direction (Fig. 1). However, it is surprising to see that particle motions for most other later phases with larger amplitudes did not occur along NW-SE, but along NE-SW (Fig. 4). This indicates that the later phases might not originate directly from the hypocenter, but are reflected or scattered from some other sources southwest of the station (KGN) (Fig. 1).

In addition to particle motion, potential scattering sources are further constrained from travel-time delays between the direct and some later phases. To estimate possible scattering sources for 11 later phases shown in Fig. 4, a grid search with $1 \mathrm{~km}$ spacing was carried out in the upper mantle at depths between 0 and $300 \mathrm{~km}$ beneath southwest of the 


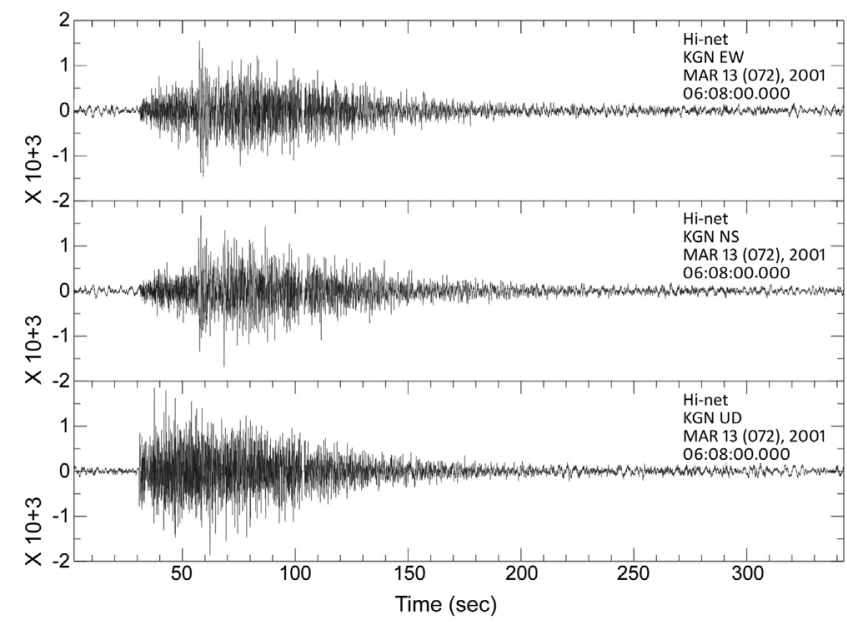

Fig. 2. Three-component seismograms recorded at Station KGN and generated by the intermediate-depth earthquake.

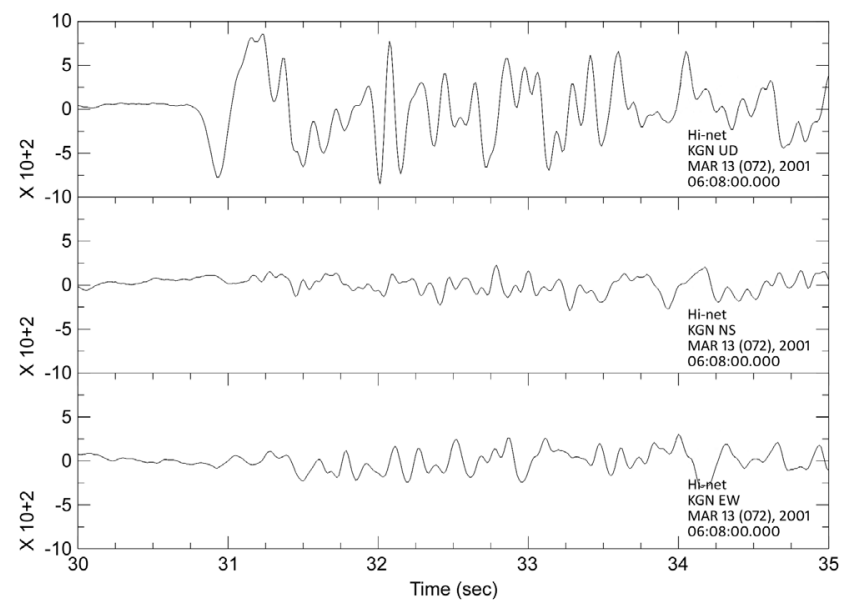

Fig. 3. Three-component seismograms during the first 5 seconds at Station KGN.

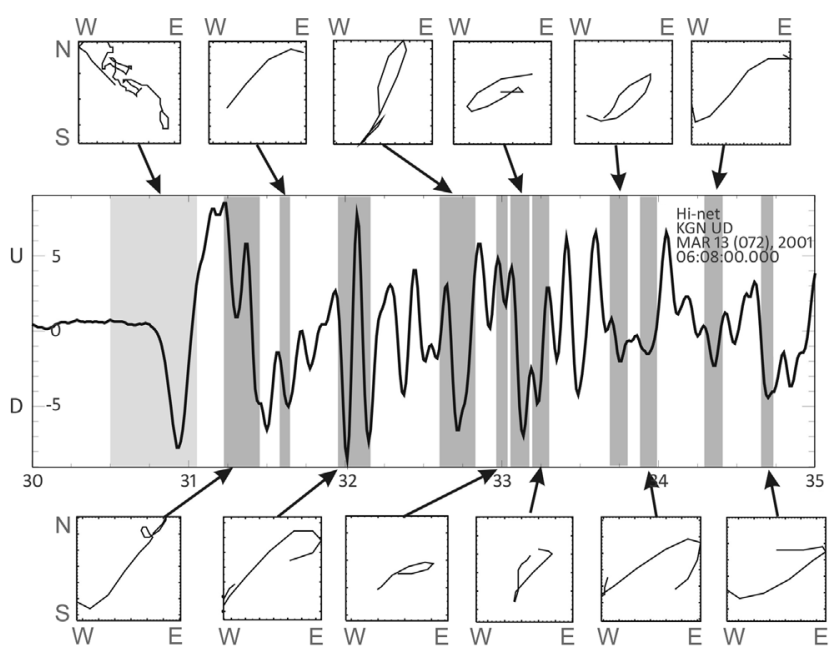

Fig. 4. Seismograms along the vertical component during the first 5 seconds (middle) at station KGN, and particle motion along the horizontal plane for the direct and 11 later phases with larger amplitude (upper and lower boxes). station (KGN). The result shows that travel-time delays for those later phases can be explained by seismic energy scattered from some particular points on a nearly vertical plane with the strike of $\mathrm{E} 15^{\circ} \mathrm{S}$ dipping to the NE (Fig. 5). For instance, the first of the later phases with travel time delays between 0.45 and 0.70 seconds (Fig. 4) are most likely reflected through scattering points along ellipses on the nearly vertical plane at depths between 70 and $160 \mathrm{~km}$. The later phases which follow appear to be more likely reflected from either a single scattering point at deeper ellipse arcs or at multiple scattering points in the upper mantle.

To identify the scattering sources from the melting slab, we examine particle motions of seismograms (Figs. 6 and 7) for the first few seconds recorded at another station, GER, which is located at the SSW to the epicentre (Fig. 1). The result shows that the particle motion of the first $\mathrm{P}$-waves is along the NNE-SSW direction (Fig. 8), that is basically consistent with the source direction. On the other hand, particle motions for many other later phases are along the NNWSSE direction. This indicates the seismic waves originated from the SSE direction, where the subducted Philippine Sea

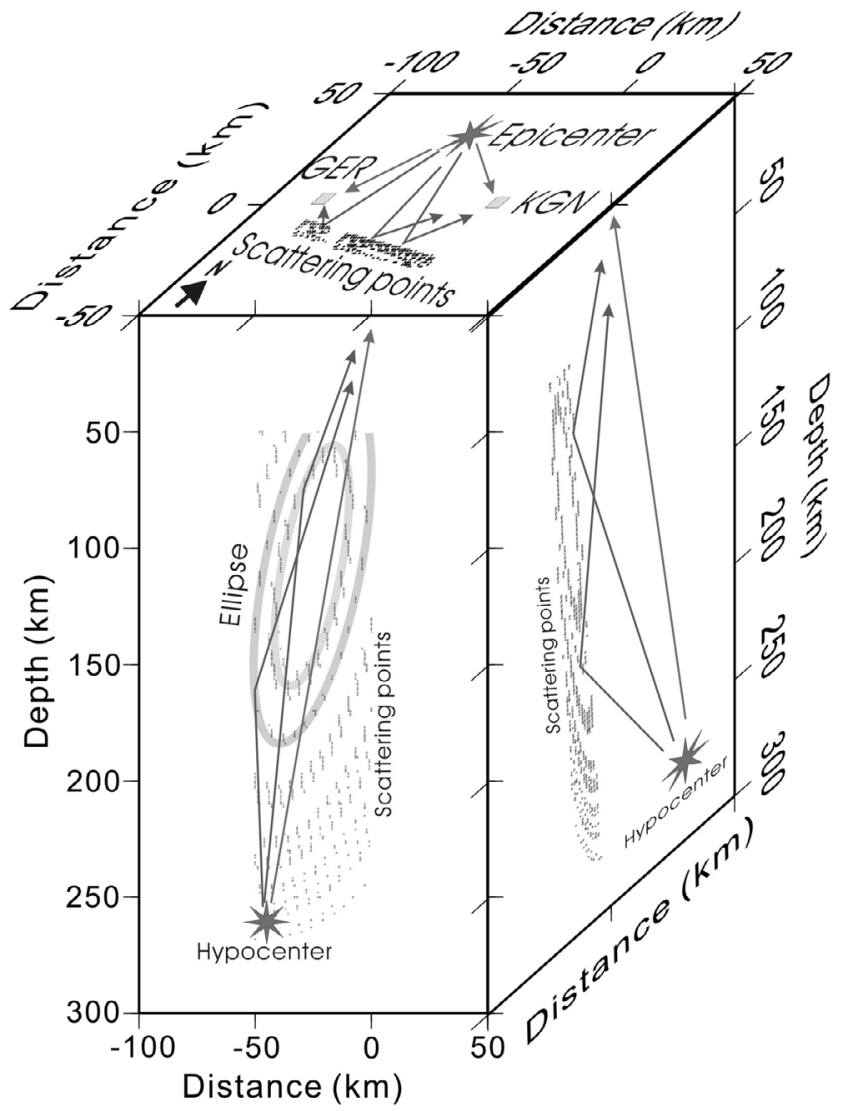

Fig. 5. Stereographic projection of potential scattering sources (small dots) and ray-paths of the direct and scattered waves from the hypocenter (a star) to Station KGN and GER (squares) in central Japan. Those scattering sources recorded at Station KGN are basically located along some ellipses, whose sizes depend on the travel-time delay between the direct and scattered waves. 


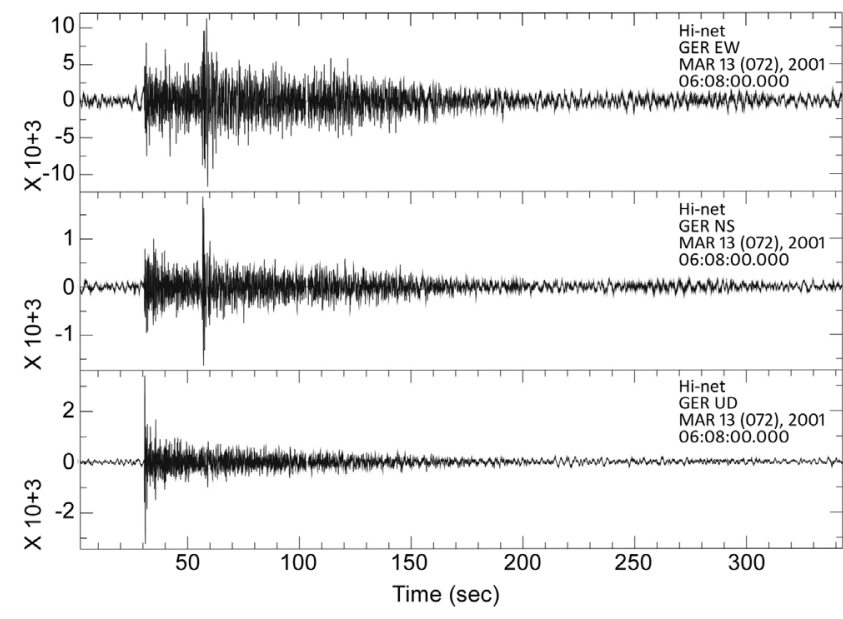

Fig. 6. Three-component seismograms recorded at Station GER and generated by the intermediate-depth earthquake.

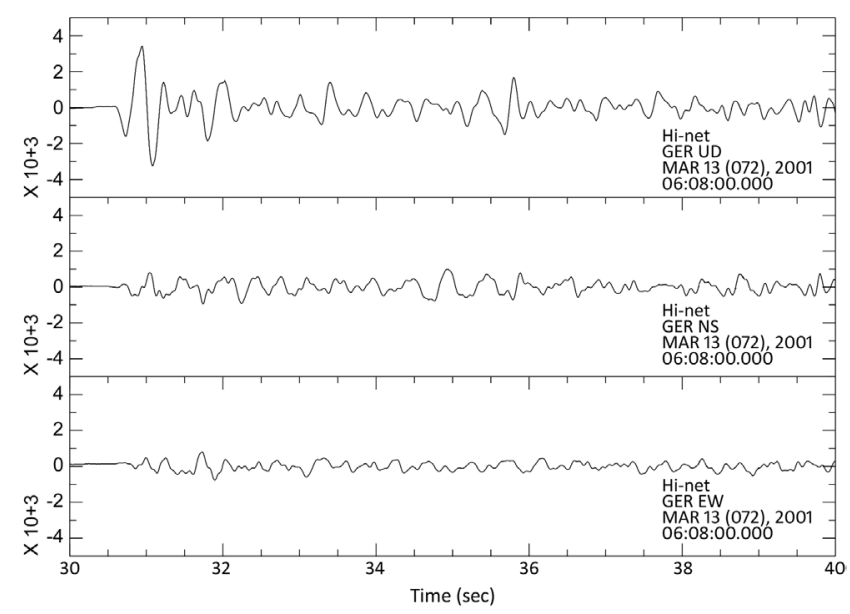

Fig. 7. Three-component seismograms during the first 5 seconds at Station GER.

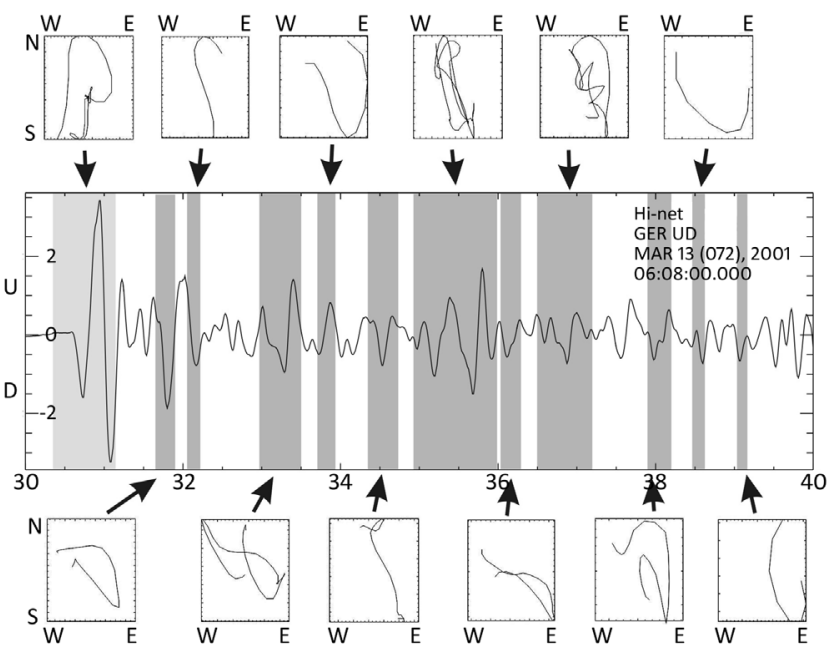

Fig. 8. Seismograms taken along the vertical component during the first 5 seconds (middle) at station GER and particle motion along the horizontal plane for the direct and 11 later phases with larger amplitude (upper and lower boxes). plate is clearly identified from the Wadati-Benioff zone at shallow depths $(0-70 \mathrm{~km})$. Combining this finding with the previous one (Fig. 4), therefore, we might expect the reflected sources for seismograms recorded at both Stations KGN and GER consistently originate from the subducted slab of the Philippine Sea plate (Fig. 5).

\section{DISCUSSION}

Several possible structures might be considered as potential candidates according to the regional tectonics in central Japan to explain anomalous seismograms with many strong scattering waves. First of all, the magma conduits or channels beneath the active volcanoes, such as Ontake volcano (Fig. 1), would be considered probable sources for generating strong scattering waves. This possibility can be ruled out not only by previous research (Lin et al. 2003), but also the new evidence in the present study. Based on the findings of Lin et al. (2003), scattering sources originate from the upper mantle. Thus, it is unlikely that the magma conduits or channels in the upper mantle beneath central Japan are reflecting seismic energy. Some new observations show that the locations of possible scattering sources associated with magma conduits or channels were not consistent with observations of polarization direction. The magma conduits or channels beneath the volcanoes are located north of stations KGN and GER, but the scattering sources estimated from particle motion are located south of the stations.

The second possibility accounting for the seismic scattering is the deep structures associated with the previous collision zone beneath the Itoigawa-Shizuoka Tectonic Line between the Eurasian plate and Okhotsh plate (Seno et al. 1996). However, it is difficult to sustain many open fractures or cracks under high lithospheric pressure in the upper mantle (Lin et al. 2003). Another possibility might be the upwelling flow of aqueous fluids, as proposed by Nakajima and Hasegawa (2007), who demonstrated mantle upwelling beneath southwestern Japan from tomographic observations. However, there is no reliable evidence to conclusively show upwelling flow beneath the Chubu area (Japan) because the low velocity $\mathrm{P}$-waves and high $\mathrm{Vp} / \mathrm{Vs}$ ratios at the scattering zone are difficult to find (Matsubara et al. 2008). Although some high helium isotope ratios were detected in the Chubu area, this was limited within a small area around the Ontake volcano (Sano and Wakita 1985).

Based upon seismic analyses here and the regional tectonics, one of the more likely scattering sources able to produce the anomalous moonquake-like seismograms in central Japan can be accounted for by partial melting within the deep zone of the Philippine Sea plate where the subducted angle increases significantly below $70 \mathrm{~km}$ (Fig. 9). The leading edge of the subducted Philippine Sea plate, mapped from earthquake distribution (Noguchi 2002), is located just south of the epicenter and stations KGN and GER (Fig. 1). 


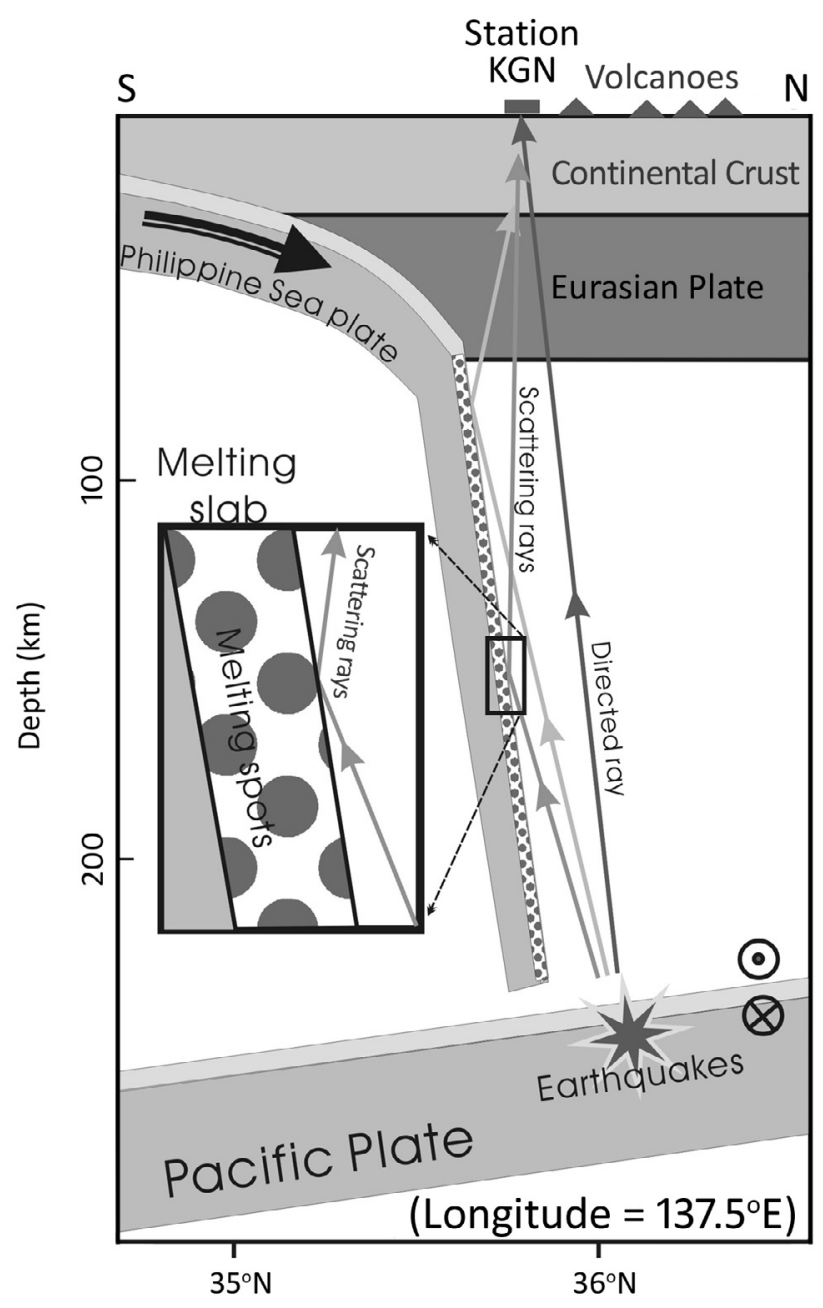

Fig. 9. Schematic plots for showing the ray-paths of both the direct wave from the hypocenter (star) to Station KGN (square) and the seismic waves scattered from the melting spots (circles) in the subducted Philippine Sea plate along cross-section of $137.5^{\circ} \mathrm{E}$. The inset map highlights a small part of the subducted slab with patches of partial melting spots and a ray-path reflected at a melting spot. The arrow indicates the movement of subducted Philippine Sea.

Should the subduction angle of the Philippine Sea plate at depths below $70 \mathrm{~km}$ increase to an almost vertical direction, as suggested by tomographic images (Honda and Nakanishi 2002; Nakamura et al. 2002), the geometry of the subducted slab could easily reflect seismic energy generated by the intermediate-depth earthquake to the nearby station (Fig. 5). Further, if partial melting took place within the subducted slab, abundant melting spots would become the seismically scattering bodies able to generate scattered reflections. The subducted slab may be then interpreted as solid eclogite with a patchy distribution of partially melted spots. Thus, melting spots in the subducted slab appear like "bright spots" during seismic exploration and would efficiently reflect (or scatter) most of the incident energy with large amplitudes (Stone 1977; Allen and Peddy 1993).

Although the geometry of the deep part of the subduct- ed Philippine Sea plate is not yet fully understood due to the absence of the deeper intraslab earthquakes within the Wadati-Benioff zone, the change of subduction angle to nearly vertical might be possible based on seismic tomography as well as seismicity. In addition to seismic tomographic imagery (Nakamura et al. 2002), seismicity at the leading edge of the Wadati-Benioff zone shows the subduction angle turning to almost vertical at depths below $50 \mathrm{~km}$ (Noguchi 2002). Also, the missed identification of the deeper intraslab earthquakes might imply that the subducted slab has lost its strength due to higher temperatures and bending caused by negative buoyancy.

From a tectonic point of view, partial melting of the subducted slab of the Philippine Sea plate is possible when examining central Japan because the Philippine Sea plate is young and therefore at high temperature before the subduction. The subsequent subduction process would significantly increase the slab temperature when it reached the depth of the upper mantle depth. As a result, partial melting might occur more readily than in other old and cold subducted slabs such as the subduction in both the southwest and the northern Japan (Peacock and Wang 1999). Unlike strong evidence for slab melting obtained from geochemical analyses of volcanic lava (Morris 1995) and thermal modelling (Peacock and Wang 1999) in southwest Japan, there were no geochemical observations to show slab melting in central Japan. However, partial melting in central Japan is more likely than in southwest Japan because the age (0 - $2 \mathrm{Ma})$ of the subducted Philippine Sea plate in central Japan is significantly younger than that $(12-25 \mathrm{Ma})$ in southwest Japan (Taylor et al. 1991). Also, the subducted Philippine Sea plate in central Japan is hotter than that in southwest Japan. The subducted slab of the Philippine Sea plate in central Japan might be heated by the ascending magma associated with the subducted Pacific plate because the volcanic front of the subduction system of the Pacific plate lays across central Japan (Noguchi 2002).

\section{CONCLUSION}

Although possible slab melting has been proposed in some young and hot subduction zones, there were no seismological observations to support a plausible mechanism due to the absence of deeper earthquakes within the young subduction zones. Careful analyses of anomalous moonquake-like seismograms recorded at Hi-net stations and generated by an intermediate-depth earthquake in central Japan show that slab melting has taken place at the deeper bending part of the subducted Philippine Sea plate. A significant increase of subduction angle to nearly vertical below $70 \mathrm{~km}$ was revealed from detailed analyses of both particle motion and travel-time delays of strong later phases recorded at two seismic stations (KGN and GER) in central Japan. The new observations in this study are consistent with the pre- 
vious results investigating possible slab melting in central Japan (Lin et al. 2003). Because the subducted Philippine Sea plate is young and hot, slab melting has taken place and generated abundant melting points, like "bright spots," in seismic exploration, to efficiently scatter (or reflect) seismic energy.

Acknowledgements I would like to thank the National Research Institute for Earth Science and Disaster Prevention (NIED) in Japan for providing valuable seismic data. This research was partially supported by the National Science Council (NSC). Valuable comments by Drs. C. H. Chan, K. $\mathrm{H}$. Kim and one anonymous reviewer are much appreciated.

\section{REFERENCES}

Allen, J. L. and C. P. Peddy, 1993: Amplitude Variation with Offset: Gulf Coast Case Studies, Geophysical Development, Vol. 4, Society of Exploration Geophysicists, Tulsa, Okla, $126 \mathrm{pp}$.

Defant, M. J. and M. S. Drummond, 1990: Derivation of some modern arc magmas by melting of young subducted lithosphere. Nature, 347, 662-665, doi: 10.1038/ 347662a0. [Link]

Honda, S. and I. Nakanishi, 2002: Shape of the Philippine Sea slab in the mantle and volcanism in the Chubu region, central Japan. Geophys. Bull. Hokkaido Univ., 65, 167-177.

Ishida, M., 1992: Geometry and relative motion of the Philippine Sea plate and Pacific plate beneath the KantoTokai district, Japan. J. Geophys. Res., 97, 489-513, doi: 10.1029/91JB02567. [Link]

Lin, C. H., M. Ando, N. Fujii, K. Yamaoka, K. Tadokoro, A. S. Jin, K. Obara, and M. Ishida, 2003: Anomalous seismograms generated by an intermediate-depth earthquake: Unusual scattering sources in the upper mantle of central Japan. Geophys. Res. Lett., 30, 1586-1589, doi: 10.1029/2002GL016837. [Link]

Matsubara, M., K. Obara, and K. Kasahara, 2008: Threedimensional P-and S-wave velocity structures beneath the Japan islands obtained by high-density seismic stations by seismic tomography. Tectonophysics, $\mathbf{4 5 4}, 86$ 103, doi: 10.1016/j.tecto.2008.04.016. [Link]

Morris, P. A., 1995: Slab melting as an explanation of Quaternary volcanism and aseismicity in southwest Japan. Geology, 23, 395-398, doi: 10.1130/0091-7613(1995) 023<0395:SMAAEO >2.3.CO;2. [Link]

Nakajima, J. and A. Hasegawa, 2007: Tomographic evidence for the mantle upwelling beneath southwestern
Japan and its implications for arc magmatism. Earth Planet. Sci. Lett., 254, 90-105, doi: 10.1016/j.epsl.20 06.11.024 . [Link]

Nakamura, M., D. Zhao, K. Yoshikawa, H. Kuroki, T. Yamazaki, J. Kasahara, T. Sato, H. Shimamura, and A. Nakanishi, 2002: Three-dimensional P and S wave velocity structure beneath central Japan. Papers Meteorol. Geophys., 53, 1-28.

Nakamura, Y., G. V. Latham, and H. J. Dorman, 1982: Apollo lunar seismic experiment - final summary. J. Geophys. Res., 87, A117-A123, doi: 10.1029/JB087iS01p 0A117. [Link]

Noguchi, S., 2002: Earthquake clusters in the Kanto and Tokai subduction zones: Implications for modes of plate consumption. In: Fujinawa, Y. and A. Yoshida (Eds.), Seismotectonics in Convergent Plate Boundary, 451-467.

Obara, K., 2002: Nonvolcanic deep tremor associated with subduction in southwest Japan. Science, 296, 16791681, doi: 10.1126/science.1070378. [Link]

Obara, K., K. Kasahara, S. Hori, and Y. Okada, 2005: A densely distributed high-sensitivity seismograph network in Japan: Hi-net by National Research Institute for Earth Science and Disaster Prevention. Rev. Sci. Instrum., 76, 021301, doi: 10.1063/1.1854197. [Link]

Okada, Y., K. Kasahara, S. Hori, K. Obara, S. Sekiguchi, H. Fujiwara, and A. Yamamoto, 2004: Recent progress of seismic observation networks in Japan - Hi-net, F-net, K-NET and KiK-net. Earth Planets Space, 56, xv-xxviii.

Peacock, S. M. and K. Wang, 1999: Seismic consequences of warm versus cool subduction metamorphism: Examples from southwest and northeast Japan. Science, 286, 937-939, doi: 10.1126/science.286.5441.937. [Link]

Sano, Y. and H. Wakita, 1985: Geographical distribution of ${ }^{3} \mathrm{He} /{ }^{4} \mathrm{He}$ ratios in Japan: Implications for arc tectonics and incipient magmatism. J. Geophys. Res., 90, 87298741, doi: 10.1029/JB090iB10p08729. [Link]

Seno, T., T. Sakurai, and S. Stien, 1996: Can the Okhotsk plate be discriminated from the North American plate? J. Geophys. Res., 101, 11305-11315, doi: 10.1029/96JB 00532. [Link]

Stone, C. B., 1977: "Bright spot" techniques. In: Hobson, G. D. (Ed.), Developments in Petroleum Geology, Appl. Sci. Publ., London, 275-291.

Taylor, B., A. Klaus, G. R. Brown, G. F. Moore, Y. Okamura, and F. Murakami, 1991: Structural development of Sumisu Rift, Izu-Bonin Arc. J. Geophys. Res., 96, 16113-16129, doi: 10.1029/91JB01900. [Link] 